\title{
Smart Home Analysis in India:An IOT Perspective
}

\author{
Chinmaya Vyas \\ SVKMs NMIMS Mumbai
}

\author{
Shashikant Patil \\ SVKMs NMIMS Mumbai
}

\begin{abstract}
This paper showcases the different technologies available for making one's home a smarter one. Lately the world has witnessed a great surge in the field of automation. With the increase in living standards of people the demand for smart homes has accentuated. So keeping in mind three main concepts of a smart home that is energy, safety and comfort, the paper brief's about smart homes as an application of IOT and consequently discussing the challenges faced by IOT during the implementation of smart homes in India. The various wireless protocols being used also find an important place in manuscript.
\end{abstract}

\section{Keywords}

Smart homes, IOT, Wireless protocols, Zigbee.

\section{INTRODUCTION}

With recent technological advancements in the world, field of home automation has seen quite a surge in its market. Homes have become quite tech savvy, a large amount of credit goes to the science fiction movies in triggering the human brain to develop such techniques which could eventually add to comfort \& safety. The technology which brought a revolution in the field of automation is Internet of Things(IOT). Internet has transformed the lives a lot and has now become a nessesity. Providing anytime connectivity is a special feature and thus integration of sensors, transmitters and receivers assisted in creation of a new avenue which was named IOT.

\subsection{Internet Of Things}

IOT is the connection of internet with several entities of real world.Connection of things to Internet via standard protocols is the best definition of IOT. In context to the topic of dicussion when several household devices in a smart home connect with internet using network architecture and standard protocols is termed as a smart home in Internet of Things(IOT)[1].

\subsection{Smart Homes}

They are intelligent systems which actually sense the surrounding and work accordingly to create a safe, efficient and comfortable ambience around.Their energy efficient and safety feature accentuates their importance in today's world which is actually an era of Intelligent systems.Smart Homes also known as Home automation can be achieved via wired as well as wireless systems.At the time of construction of a house wired installations are done to provide home automation facilities through a wired mode and thus making the installation easier. Whereas wireless technology relies on the preinstalled wired structures at your home such as power lines and phone lines though their installation is a little tedious process but it is more convienent and less invasive and provides better services considering the proliferation of smart phones and smart home appliances. One of the main objective of home automation systems is saving energy or power, as it is well known that a large amount of electricity is being wasted each day just due to human negligence which can be curbed just by developing the system which monitors the area and automatically switches off the devices when there is no one in the room also integration of temperature sensors gives an advantage of controlled output from both light and fan according to the temperature of the room .Now considering another aspect that is safety due to the ever increasing old people and children's population there is a need for the homes to be smarter one so that it can provide safer environment for them. The paper discusses about the developments made in the field of home automation,basic requirements of wireless protocols and a comparitive analysis between the existing wireless protocols, the challenges faced in the implementation of IOT technology in home automation and then finally the analysis of the difficulties faced by smart homes in India.

\section{RELATED WORKS}

A Plethora of research has been done in the field of home automation applied to the concept of smart homes.Developments in the related field have been summarised and also inspection of their limitations has been done in this section.Home automation is a the controlling of the various devices, household appliances and residential home features like doors,gate and windows[2]. Golay Marcel J.E[3] developed bidirectional counters which kept a count of no of persons in a room and lights and fans were turned off when there was no one in the room and automatically switches on the light when a person enters the room.Wein Yan et.al [4] developed a central energy saving unit.TF Rahaman et.al[5] constructed a wireless sensing system for smoke and fire detection.Further several other works were carried out considering the safety issues like LPG Leakage [6].There was a major achievment in 1975 when X10[7] wireless technology was invented and there was a major shift from the traditional wired medium to the wireless ones. Then eventually wireless systems developed and then Bluetooth based home automation[8] had a high data rate but had latency issues.Hand gesture based [9] home automation developed by T.baudel et.al also had inaccuracy problems.Wifi[15] based systems had a demerit that the costs and power consumption was high.Zigbee[11] based home automation techiques are very popular these days due to high data rate no sort of latency issues.

\section{WIRELESS SYSTEMS}

Wireless systems have always been harbingers of change in the home automation systems. Wireless sensor networks is a group of nodes which are systemized into a cooperative network with each node containing a processing ability, several memory types, a RF transreceiver and a source of power[12].Wireless communication is very handy and since it does not require any wiring thus improving a system's scalability. The operation of the wireless systems is also very fast. Since a common protocol is adopted worldwide for the system configuration it makes it easy to install and configure. Salient features of wireless technologies include low data rate, long battery life, less complex protocols.

\subsection{Wireless protocol design}

Basic requirements for wireless protocol design are: 


\subsubsection{Network services}

The most initial requirement of a wireless system design is it must support the different types of traffic pattern since a system may be congested or may be idle at any instant and thus developing this aspect is a quality control mechanism . Real time alarm property and low power consumption are primary requirements.

\subsubsection{Indoor radio planning:}

With various reflective surfaces present inside the house there exist several multipath and they are typically characterised by the shiny reflective surfaces only [13].

The demerit being its inefficiency and low accuracy in the radio planning design techniques which can actually trigger high logistics cost. New installations may be unacceptable because of great deal of shifting to increase the coverage area and it is also very time consuming.

\subsubsection{Low duty cycle operation:}

Since the wireless devices are generally battery operated devices. When they are placed at certain spots then it should remain active for 3-6 yrs. in order to be called efficient devices. Hence there must be some sort of constraints on the radio transreceiver and sensors for minimizing energy consumption. Optimisation is indeed needed in order to save battery thus the best possible solution to the problem here is dynamic sleep mode activation so that the battery power is saved.

\subsection{Wireless protocols for home and building automation}

Showcases a review of the wireless networking in home automation system:

Table 1: Commercial wireless systems and standards used for home automation [23].

\begin{tabular}{|c|c|c|c|c|c|}
\hline $\begin{array}{l}\text { Protoco } \\
1\end{array}$ & $\begin{array}{l}\text { Freque } \\
\text { ncy } \\
\text { band }\end{array}$ & $\begin{array}{l}\text { Dat } \\
\text { a } \\
\text { rate }\end{array}$ & $\begin{array}{l}\text { Modu } \\
\text { lation }\end{array}$ & $\begin{array}{l}\text { Sec } \\
\text { urit } \\
y\end{array}$ & $\begin{array}{l}\text { Max } \\
\text { Stac } \\
k \\
\text { size }\end{array}$ \\
\hline Zigbee & $\begin{array}{l}2400 \\
915868\end{array}$ & 250 & $\begin{array}{l}\text { O- } \\
\text { QPSK } \\
\text { BPSK } \\
\end{array}$ & $\begin{array}{l}\text { AES } \\
- \\
128 \\
\end{array}$ & 128 \\
\hline $\begin{array}{l}\text { Z- } \\
\text { WAVE }\end{array}$ & $\begin{array}{l}2400 \\
915868\end{array}$ & 200 & $\begin{array}{l}\text { FSK } \\
\text { GFSK }\end{array}$ & $\begin{array}{l}\text { AES } \\
- \\
128\end{array}$ & 64 \\
\hline $\begin{array}{l}\text { EN } \\
\text { OCEN }\end{array}$ & 868 & 125 & ASK & $\mathrm{NO}$ & 24 \\
\hline $\begin{array}{l}\text { WAV } \\
\text { NIS }\end{array}$ & $\begin{array}{l}915868 \\
433\end{array}$ & 100 & $\begin{array}{l}\text { GFSK } \\
\text { PSK }\end{array}$ & $\begin{array}{l}\text { DES } \\
-3 \\
\text { AES } \\
-128\end{array}$ & - \\
\hline MIWI & $\begin{array}{l}2400 \\
950915 \\
868\end{array}$ & 200 & FSK & $\mathrm{NO}$ & 25 \\
\hline $\begin{array}{l}\text { INSTO } \\
\mathrm{N}\end{array}$ & 904 & 38.4 & FSK & $\begin{array}{l}\text { Roll } \\
\text { ing } \\
\text { code }\end{array}$ & 7 \\
\hline $\begin{array}{l}\text { KNX- } \\
\text { RF }\end{array}$ & 868.3 & 16.4 & FSK & $\mathrm{NO}$ & - \\
\hline
\end{tabular}

Table 2: Merits and Demerits of various Wireless Systems [23].

\begin{tabular}{|c|c|c|c|}
\hline $\begin{array}{l}\text { Wirele } \\
\text { ss } \\
\text { protoc } \\
\text { ol }\end{array}$ & $\begin{array}{l}\text { Developed } \\
\text { by }\end{array}$ & Merits & Demerits \\
\hline $\begin{array}{l}\text { Blueto } \\
\text { oth }\end{array}$ & $\begin{array}{l}\text { Bluetooth } \\
\text { special interest } \\
\text { group, Kirkland } \\
\text { Washington, } \\
\text { USA }\end{array}$ & $\begin{array}{l}\text { Can connect } \\
\text { various } \\
\text { controllers } \\
\text { and sub } \\
\text { controllers in } \\
\text { a star } \\
\text { topology [14]. }\end{array}$ & $\begin{array}{l}\text { Shows } \\
\text { access } \\
\text { delay. }\end{array}$ \\
\hline Zigbee & $\begin{array}{l}\text { Zigbee alliance, } \\
\text { San Rannon, } \\
\text { CA, USA }\end{array}$ & $\begin{array}{l}\text { Low data rate } \\
{[15] \text { and short }} \\
\text { range } \\
\text { applications. } \\
\text { Cost effective } \\
\text { wireless } \\
\text { sensing. }\end{array}$ & $\begin{array}{l}\text { Limited } \\
\text { application } \\
\text { in electrical } \\
\text { devices } \\
\text { such as } \\
\text { wireless } \\
\text { switches } \\
\text { and } \\
\text { sensors. }\end{array}$ \\
\hline $\mathrm{Z}$ wave & $\begin{array}{l}\text { Zen } \\
\text { systems,Hillsbo } \\
\text { rough,USA }\end{array}$ & $\begin{array}{l}\text { Whole route } \\
\text { of the data } \\
\text { packet is } \\
\text { already } \\
\text { defined due to } \\
\text { mesh } \\
\text { networking } \\
\text { approach } \\
{[16] .}\end{array}$ & $\begin{array}{l}\text { Large } \\
\text { amount of } \\
\text { data cannot } \\
\text { be } \\
\text { transferred. } \\
\text { Real time } \\
\text { data } \\
\text { transmissio } \\
\text { n not } \\
\text { possible. }\end{array}$ \\
\hline $\begin{array}{l}\text { En } \\
\text { ocean }\end{array}$ & $\begin{array}{l}\text { En ocean } \\
\text { alliance San } \\
\text { Rannon, CA, } \\
\text { USA }\end{array}$ & $\begin{array}{l}\text { Self-powered } \\
\text { wireless } \\
\text { devices } \\
\text { [17].Optimise } \\
\text { d for energy } \\
\text { saving. }\end{array}$ & $\begin{array}{l}\text { Transmissi } \\
\text { on is not } \\
\text { reliable. } \\
\text { No security } \\
\text { mechanism. }\end{array}$ \\
\hline $\begin{array}{l}\text { Waven } \\
\text { is }\end{array}$ & $\begin{array}{l}\text { Crononis } \\
\text { Systems, Perols, } \\
\text { France. }\end{array}$ & $\begin{array}{l}\text { Monitoring } \\
\text { and control } \\
\text { operation[18] } \\
\text { Uses Low } \\
\text { power radio } \\
\text { systems. }\end{array}$ & $\begin{array}{l}\text { Small } \\
\text { number of } \\
\text { functions } \\
\text { and suitable } \\
\text { for only } \\
\text { low end } \\
\text { application. }\end{array}$ \\
\hline Insteon & $\begin{array}{l}\text { Smart Labs Inc. } \\
\text { Irvine,CA,USA }\end{array}$ & $\begin{array}{l}\text { Master } \\
\text { controller is } \\
\text { not required } \\
\text { each device is } \\
\text { self-sufficient } \\
\text { to transmit, } \\
\text { receive and } \\
\text { repeat any } \\
\text { message } \\
\text { complaint } \\
\text { [19]. }\end{array}$ & $\begin{array}{l}\text { Not many } \\
\text { products } \\
\text { available in } \\
\text { the market. }\end{array}$ \\
\hline $\begin{array}{l}\text { KNX- } \\
\text { RF }\end{array}$ & $\begin{array}{l}\text { KNX } \\
\text { Association } \\
\text { Cvba, Diegen, } \\
\text { Belgium. }\end{array}$ & $\begin{array}{l}\text { High data } \\
\text { reliability } \\
\text { Transmitted } \\
\text { data is not } \\
\text { subject to } \\
\text { integrity } \\
\text { check. }\end{array}$ & $\begin{array}{l}\text { Not } \\
\text { suitable for } \\
\text { radio } \\
\text { frequency } \\
\text { communica } \\
\text { tion. } \\
\text { No security } \\
\text { mechanism. }\end{array}$ \\
\hline
\end{tabular}

The two tabular representations show general overview regarding the various wireless protocols used for home automation. Elements considered while comparative analysis were: Frequency bands, data rates, modulation techniques, routing schemes, topologies and then eventually their merits and demerits. On a concluding note when compared to Zigbee range of Wavenis is more and consumes low power [17]. $Z$ wave may be considered as an alternative of Zigbee due to 
effective energy management, low power consumption and increased battery life. But still Zigbee remains the most popular wireless protocol high data rates and stack size among all the other options available. Low cost, high reliability adds to its credentials and makes it the most preferred device for the home automation techniques.

\section{CHALLENGES FACED BY IOT}

Increased number of applications under the internet of things is a major challenge faced as the system becomes more complex. With the increased application comes the problem of connectivity [20]. 3G services are used for the connectivity purpose. Every time availability of the signal is practically not possible with so many connectivity problems.

Key challenges faced by IOT are:

\section{1) Standards}

Reliability of the system is a major issue. A reliable system is must for any technology. The data should be transmitted from the source to the destination without any error, delay or loss.

\section{2) Identification}

Unique identification is a big problem faced by IOT and as it is evident that smart homes based on IOT have low security at the server side.

\section{3) Privacy}

User data should be confidential and must not be disclosed and kept safe from external interventions.

\section{4) Authentication}

To secure smart homes from attacks. This is a major preventive step that should be taken in order to insure safety of the data.

\section{5) Security}

The ability of the system to reconfigure itself in accordance with the possible threats in order to be safe.

\section{6) Integration}

Integration of several devices each day not only increases the system complexity but also causes connectivity problems. So the environment should be such that integration should not affect the performance of other systems.

\section{7) Co-ordination}

The globally connected objects, process etc. should have a proper co-ordination between them in for the ease in data transmission and other works.

\section{8) Data storage}

With the ever increasing applications of IOT has created a problem of increasing amount of data. It indeed poses a challenge to store the data. Artificial intelligence is extensively used in order to tackle this problem.

\section{9) Self-organisation of network}

The connected networks should devise their own connection and self-organise itself so that in future there is no data loss due to network failure.

\section{0) Cost effectiveness}

Almost every device has to face this problem. Since in the smart home technology the products devised are quite expensive. Thus proliferation of the devices is a tough job.

\section{SMART HOMES IN INDIA: MARKET ANALYSIS}

Smart homes once hailed as the domain to rich are now slowly and steadily becoming a necessity for the common man in urban areas. The security and automatic control features seem to have attracted many households.Intially smart homes were marketed for the advanced security features it provided but nowadays lightening, gas leakage detection, fire detection are some of the advanced features which have been incorporated which has certainly fuelled up the demand of smart homes in India. It is estimated that smart homes are growing at a rate of 30 percent and the market revenue will double in the next 3 years. Due to the increase in working couples the demand of energy efficient and safe homes has accentuated lately in metro cities.

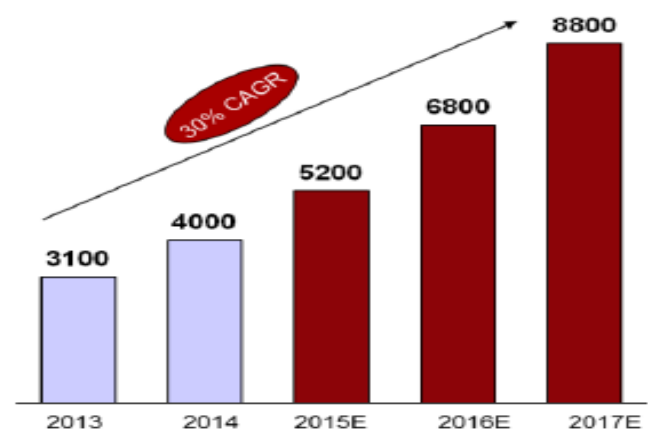

Figure 1: Home automation market growth in India [22].

In India all upper homes house owners want to go for smart homes. Even the middle class homes want to go for the smart home solutions. From the market analysis done by Schneider electric it was found that only two features namely security and lightening control were popular among the Indian market. Other features of smart homes include:

1) Entertainment- content sharing and audio video control.

2) Electrical control- AC controls and few other smart gadgets control.

3) Communication tools- communication with the front door and main gate.

4) Security-Video, Gas leakage, smoke sensor, curtain sensor, intrusion sensor, fire sensor.

Hence the popularity of other features is quite low and hence maximum utilisation of the smart home technology is not being done.

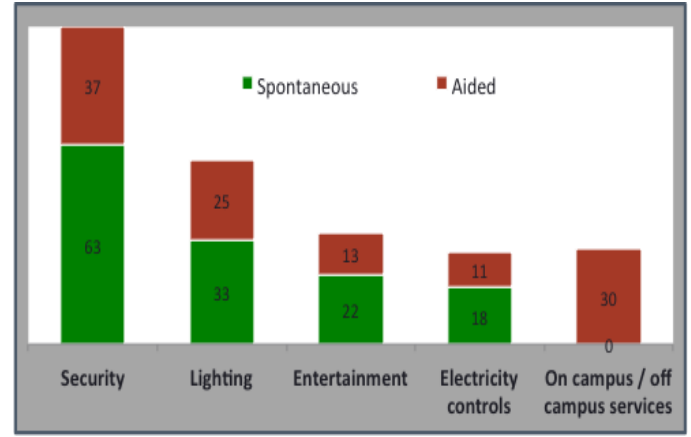

Figure 2: Awareness of customers regarding various smart home features [21]. 


\section{CONCLUSION AND FUTURE SCOPE}

In the paper we discussed about smart homes, challenges faced by IOT in implementing the concept of smart homes, various wireless protocols suitable for implementing the concept and then a small market analysis of smart homes in India. In a nutshell paper presents problems and Challenges that already exists and which could be faced in future. Zigbee is a leading wireless protocol which can be used in the home automation due to high latency and data rates. The application of Zigbee should be increased in order to increase its popularity in the smart home industry. As mentioned IOT should be made more reliable, secure and integrated system and also data management system should be strengthened in order to handle the increasing applications.IOT based Smart homes have low security at the server side hence KERBEROS technology can be used to make the environment secured from the security perspective.

Now since Digital India campaign is at full swing plus few cities in India have chosen to be developed as smart cities or future cities as they say the smart home feature certainly is a major factor because it would determine the living conditions of the people in the city. Hence promotion of smart homes with their new features would be helpful in order to give a boost to the smart home industry in the Indian market. Awareness can be created among the people by the builders to boost the technology while presenting the model flats. Increased demand will automatically create a necessity. We can take the example of smart phones which were not very popular initially and were termed as luxury devices but now it has become a necessity of each and every family member of the house. Cross device connectivity, voice command monitoring, interconnection of smart home devices are some of the advanced features which should be promoted. As far as Non metro cities are considered where problems like high cost and lack of awareness about the smart home industry exist there the cost should be subsidised by the government or the technology should get cheaper. India is a developing economy with high energy needs and smart homes present an excellent solution for energy conservation with the aid of technology we can save large amount of electricity which can be used in near future for several other purpose. Hence promotion of smart homes should be encouraged in India to make it digitalised, safe and efficient.

\section{ACKNOWLEDGMENTS}

Authors would like to express their gratitude towards Hon. Chancellor SVKMs NMIMS; Management; Higher Authorities and Faculty Members for their kind co-operation and sincere thanks to industry persons and fellow colleagues for their kind attention and time.

\section{REFERENCES}

[1] S. Giroux, and H. Pigot. "From Smart Homes to Smart Care: ICOST 2005 (Assistive Technology \& Research)". IOS Press, USA, 2005.

[2] Individual Control Home Automation System, [Online] Available: http://www.slideshare.net/olafusimichael/500project1.

[3] Golay and Marcel J.E., "The Logic of Bidirectional Binary Counters," IRE Transactions on Electronic Computers, vol.EC-6, pp.1-4, August 2009Tavel, P. 2007 Modeling and Simulation Design. AK Peters Ltd.

[4] Wei Yan and S.Y.R. Hui , "Dimming Characteristics of Large-scale High-Intensity-Discharge (HID) Lamp
Lighting Networks using a Central Energy-Saving System," Industry Applications Conference,2006, vol.3, pp.1090-1098,2006.

[5] Lipu, M.S.H., Karim, T.F., Rahman, M.L. and Sultana, F., "Wireless security control system \& sensor network for smoke \& fire detection," IEEE International Conference on Advanced Management Science(ICAMS), vol.3, pp.153-157, 2010.

[6] Ricquebourg, Vincent, David Menga, David Durand, Bruno Marhic, Laurent Delahoche, and Christophe Loge. "The smart home concept: our immediate future." In ELearning in Industrial Electronics, 2006 1ST IEEE International Conference on, pp. 23-28. IEEE, December 2006.

[7] Withanage, C. ; Ashok, R. ; Chau Yuen ; Otto, K., "A comparison of the popular home automation technologies", Innovative Smart Grid Technologies Asia (ISGT Asia), 2014.

[8] Disabled World: Disability News \& Information. Retrieved from http://www.disabled-world.com

[9] T. Baudel and M. Beaudouin-Lafon, "Charade: remote control of objects using free-hand gestures", Communications of the Association for Computing Machinery(ACM), vol. 36, no. 7, pp. 28-35, 1993.

[10] Bisio,I; Lavagetto,F; Marchese,M, "Smartphone-centric ambient assisted living platform for patients suffering from comorbities monitoring", Communications Magazine,IEEEVol:53,Issue:1,DOI:10.1109/MCOM.201 5.7010513,2015,Page(s):34-41.

[11] C. Zhang, M. Zhang, Y. Su, W. Wang " Smart home design based on ZigBee wireless sensor network", in Proceedings of $20127^{\text {th }}$ International ICST Conference on Communications and Networking in China (CHINACOM), pp. 463-466, 2012.

[12] Karl, H., \& Willing, A. "Protocols and Architectures of Wireless Sensor Networks", John Wiley \& Sons, West Sussex, England. 2007.

[13] C Gomez, J Paradells, Wireless home automation networks: A survey of architectures and technologies. IEEE Commun. Mag. 48(6), 92-101 (2010).

[14] N Sriskanthan, F Tan, A Karande, Bluetooth based home automation system. Microprocess. Microsy. 26(6), 281289 (2002)

[15] K Gill, S-H Yang, F Yao, X Lu, A ZigBee-based home automation system. IEEE Trans. Consum. Electron. 55(5), 422-430 (2009).

[16] T Jorgensen, NT Johansen, Z-wave as home control RF platform, http:// www.zen-sys.com/. Accessed Sept 2012.

[17] J Ploennigs, U Ryssel, K Kabitzsch, Performance analysis of the EnOcean wireless sensor network protocol, in Proceedings of the IEEE Conference on Emerging Technologies and Factory Automation (ETFA) (Bilbao, 13-16 Sept 2010).

[18] C Gomez, J Paradells, Wireless home automation networks: A survey of architectures and technologies. IEEE Commun. Mag. 48(6), 92-101 (2010). 
[19] RJ Robles, TH Kim, A review on security in smarthome development. Int. J. Adv. Sci. Technol. 15(2), 1322 (2010).

[20] Robert L. Boylestad \& Louis Nashelsky, Electronic devices \& circuit theory, 7th Edition, 1999, ISBN: 0-13973777-4, pp (829-832), accessed in May 2012

[21] http://www.schneiderelectric.co.in/documents/buildings/ Smart_Homes_in_India_White_Paper.pdf.
[22] http://redseerconsulting.com/sites/default/files/Home $\% 20$ Automation\%20market\%20in\%20India.pdf

[23] Milo Spadacini , Stefano Savazzi and Monica Nicoli, Wireless home automation networks for indoor surveillance: technologies and experiments, EURASIP Journal on Wireless Communications and Networking 2014, 2014:6 